\title{
Mode I stress intensity factor with various crack types
}

\author{
Ehab Samir Mohamed Mohamed Soliman \\ Mechatronics and Robotics Department, Faculty of Engineering, Egyptian Russian University, Badr City, Cairo, 11829, Egypt. \\ swgezumo@yahoo.com, bttps:/ /orcid.org/0000-0001-6427-3022
}

\begin{abstract}
Presence of cracks in mechanical components needs much attention, where the stress field is affected by cracks and the propagation of cracks may be occurred causing the damage. The objective of this paper is to present an investigation of crack type effect on crack severity in a finite plate. Three cases of cracked plate with three different types of cracks are assumed in this work, i.e., single edge crack, center crack and double edge crack. 2D numerical models of cases of cracked plate are established in finite element analysis (FEA), ANSYS software by adopting PLANE 183 element. Values of FEA mode I stress intensity factor SIF and Von-Mises stress at crack apex are determined for cases of cracked plate under tensile stress with different values. To identify the crack severity, the comparison of FEA results for different cracked cases is made. The comparison showed that, single edge cracked plate (SECP) has the maximum values of mode I SIF and Von-Mises stress at crack apex, i.e. the greatest crack severity is considered. Also, values of FEA Von-Mises stress at crack apex for center cracked plate (CCP) are moderate and for double edge cracked plate (DECP) are the minimum. Besides, in case of high crack lengths, it is found that, FEA results of mode I SIF in case of (CCP) are higher than those of in case of (DECP). Consequently, crack severity is considered as moderate in case of (CCP) and the minimum in case of (DECP). Empirical formulas are used to approximately estimate mode I SIF for all the case studies of cracked plate in this study and the results are compared to those of FEA. A good agreement between analytical and FEA results has been showed by this comparison.
\end{abstract}

KeYwords. Stress Intensity Factor (SIF); Cracked Plate; Crack Severity; VonMises Stress; Crack Apex.

\section{open 1 access}

Citation: Soliman, E.S.M.M., Mode I stress intensity factor with various crack types, Frattura ed Integrità Strutturale, xx (2022) 471-485.

Received: 01.10 .2021

Accepted: 09.12.2021

Published: 01.01.2022

Copyright: (C) 2022 This is an open access article under the terms of the CC-BY 4.0, which permits unrestricted use, distribution, and reproduction in any medium, provided the original author and source are credited.

\section{INTRODUCTION}

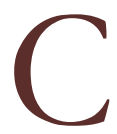

racks in engineering components often cause serious local stress concentration and may finally cause to fracture damage and consequently to failure of these components [1]. The failure of cracked components is due to the propagation of cracks and the singular (first term) stress near the crack tip is characterized by the stress intensity 
factor SIF [2]. In an elastic body, the stress intensity factors refer to the stress singularities arising from the crack tips and specify stress fields near crack tips [3]. The failure of material due to the presence of cracks can be predicted by evaluation of an important parameter in fracture mechanics i.e. stress intensity factor (SIF) [4]. In the application of the principles of linear elastic fracture mechanics to practice, the stress intensity factor (SIF) plays a vital role and hence the determination of its value is crucial important [5]. Many researchers have investigated the evaluation of stress intensity factor for cracked plate using finite element method [6-9]. Ismail et al. [10] modeled single edge cracked plate and calculated the stress intensity factors of mode I and mode II at different crack slanted angles using ANSYS finite element program. Their study showed that, higher relative crack depths produced higher stress intensity factors for mode I and mode II. They concluded that, when the crack slanted angles is increased, then the mode I stress intensity factors reduce and the mode II stress intensity factors increase. The stress intensity factors are the most important parameters in fracture analysis and provide fundamental information on how the crack is going to propagate in the elastic fracture analysis [11]. In the fracture mechanics field, the mode I stress intensity factor is a key parameter and the knowing of whether the crack is stable or not in respect to the toughness of the KIC material, is predicted by it [12]. The plane strain fracture toughness (KIC) is defined as a material property which measures crack resistance, where the crack propagation occurs when mode I SIF $\geq \mathrm{KIC}$, which is a failure criterion for brittle materials [13]. The stress intensity factor is affected by the different parameters such as crack length, crack location in the geometry, crack inclination, number of cracks and boundary conditions [14]. Ensure of the reliability and integrity of mechanical structures, can be determined by successfully using of the stress intensity factor (SIF), which is one of the most important cracks driving force [15]. Zhu et al. [16] introduced a new approach to calculate stress intensity factors for three different cases of cracked plate by using peridynamic (PD) theory and displacement extrapolation method (DEM). In the analysis, they considered plate with a central crack, plate with an edge crack and plate with a slanted crack as three problems. They compared SIFs results of proposed approach against analytical and FEM results and the comparison showed a good agreement. Mohsin [17] calculated the stress intensity factors mode I for finite center cracked plate subjected to uniform tensile loading, by finite element and analytical solution for different crack lengths and plate dimensions. He inferred that, the value of mode I intensity factor increased as the crack length and applied stresses increased. The severity of the crack is denoted by the stress intensity factor [18], so in the present work, evaluation of mode I SIF using finite element method is carried out to investigate the effect of crack type on crack severity in a 2D finite plate subjected to tensile uniaxial loading. For this purpose, the 2D numerical models of single edge cracked plate (SECP), center cracked plate (CCP) and double edge cracked plate (DECP) are developed using finite element analysis (FEA), ANSYS. FEA results of mode I SIF and Von-Mises stress at crack apex are obtained for the three cases of cracked plate and the FEA results are compared. Also, analytical solution for mode I SIF for the cases of cracked plate is carried out and a comparison between FEA results of mode I SIF and those of analytical for cases of cracked plate is made. A flow chart of this present work structure is shown in Fig. 1.

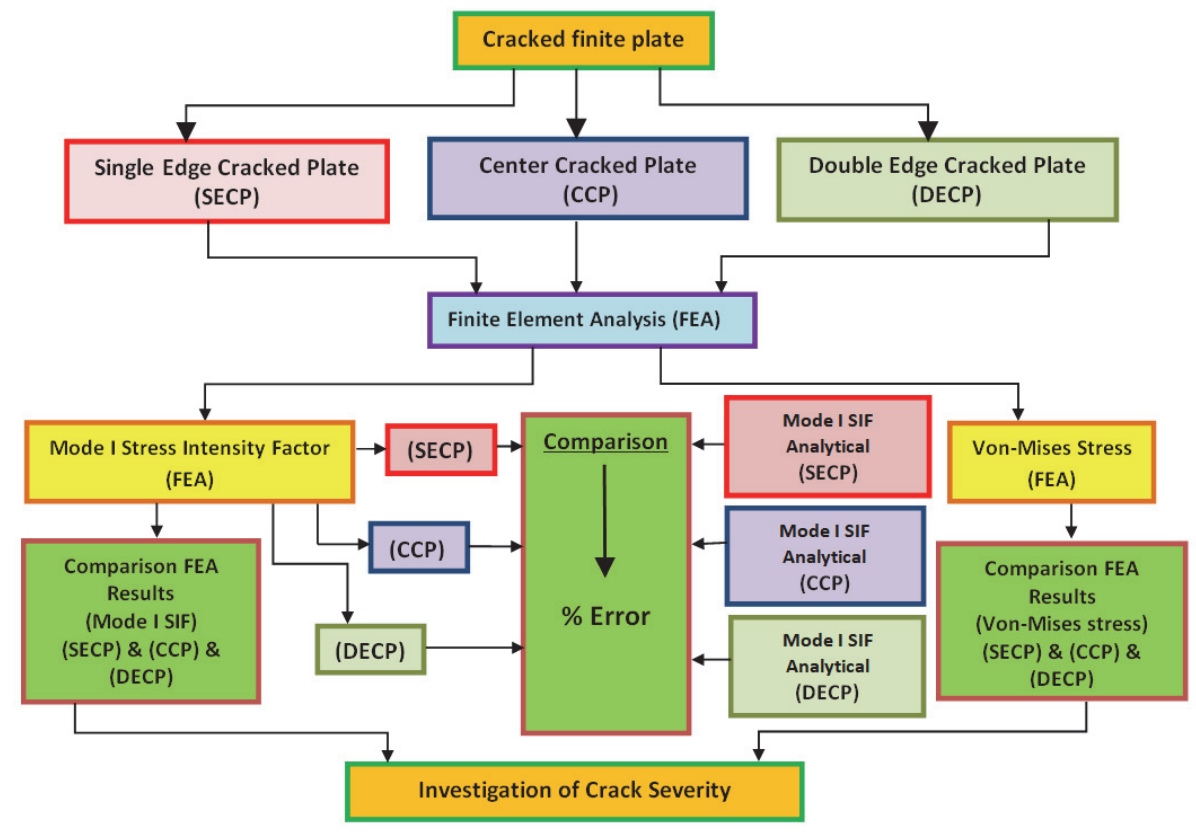

Figure 1: Flow chart of the present work 


\section{GOVERNING EQUATIONS}

$\mathrm{I}$

$\mathrm{n}$ this study, the displacement and stresses near the crack apex are described. Consequently, the co-ordinate systems and contour around the crack apex are adopting as depicted in Fig. 2.

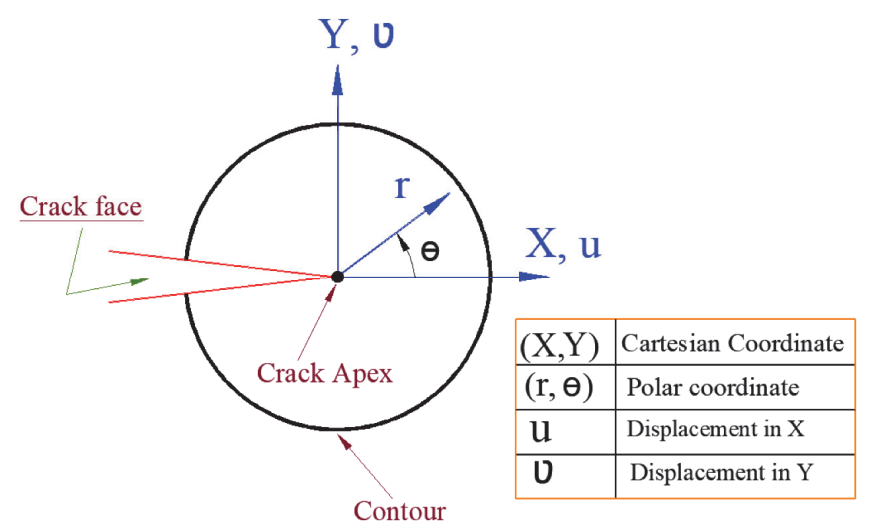

Figure 2: Crack apex co-ordinate systems

The displacement and stress fields near the tip of the crack with traction-free faces known as Williams expansion, originally introduced by [19-21] and can be written as [22]:

$$
\begin{aligned}
& u=u_{0}+y \theta_{0}+\sum_{n=1}^{\infty} \frac{r^{\frac{n}{2}}}{2 \mu}\left\{a_{n}\left[\left(k+\frac{n}{2}+(-1)^{n}\right) \cos \frac{n}{2} \theta-\frac{n}{2} \cos \left(\frac{n}{2}-2\right) \theta\right]\right. \\
& \left.-b_{n}\left[\left(k+\frac{n}{2}-(-1)^{n}\right) \sin \frac{n}{2} \theta-\frac{n}{2} \sin \left(\frac{n}{2}-2\right) \theta\right]\right\} \\
& v=v_{0}+x \theta_{0}+\sum_{n=1}^{\infty} \frac{r^{\frac{n}{2}}}{2 \mu}\left\{a_{n}\left[\left(k-\frac{n}{2}-(-1)^{n}\right) \sin \frac{n}{2} \theta+\frac{n}{2} \sin \left(\frac{n}{2}-2\right) \theta\right]\right. \\
& \left.+b_{n}\left[\left(k-\frac{n}{2}+(-1)^{n}\right) \cos \frac{n}{2} \theta+\frac{n}{2} \cos \left(\frac{n}{2}-2\right) \theta\right]\right\} \\
& \sigma_{x}=\sum_{n=1}^{\infty} \frac{n}{2} r^{\frac{n}{2}-1}\left\{a_{n}\left[\left(2+\frac{n}{2}+(-1)^{n}\right) \cos \left(\frac{n}{2}-1\right) \theta-\left(\frac{n}{2}-1\right) \cos \left(\frac{n}{2}-3\right) \theta\right]\right. \\
& \left.-b_{n}\left[\left(2+\frac{n}{2}-(-1)^{n}\right) \sin \left(\frac{n}{2}-1\right) \theta-\left(\frac{n}{2}-1\right) \sin \left(\frac{n}{2}-3\right) \theta\right]\right\} \\
& \sigma_{y}=\sum_{n=1}^{\infty} \frac{n}{2} r^{\frac{n}{2}-1}\left\{a_{n}\left[\left(2-\frac{n}{2}-(-1)^{n}\right) \cos \left(\frac{n}{2}-1\right) \theta+\left(\frac{n}{2}-1\right) \cos \left(\frac{n}{2}-3\right) \theta\right]\right. \\
& \left.-b_{n}\left[\left(2-\frac{n}{2}+(-1)^{n}\right) \sin \left(\frac{n}{2}-1\right) \theta+\left(\frac{n}{2}-1\right) \sin \left(\frac{n}{2}-3\right) \theta\right]\right\}
\end{aligned}
$$




$$
\begin{aligned}
& \tau_{x y}=\sum_{n=1}^{\infty} \frac{n}{2} r^{\frac{n}{2}-1}\left\{a_{n}\left[\left(\frac{n}{2}-1\right) \sin \left(\frac{n}{2}-3\right) \theta-\left(\frac{n}{2}+(-1)^{n}\right) \sin \left(\frac{n}{2}-1\right) \theta\right]\right. \\
& \left.\quad+b_{n}\left[\left(\frac{n}{2}-1\right) \cos \left(\frac{n}{2}-3\right) \theta-\left(\frac{n}{2}-(-1)^{n}\right) \cos \left(\frac{n}{2}-1\right) \theta\right]\right\} \\
& \mu=E /(2(1+v)) \\
& k= \begin{cases}3-4 v & \text { plane strain } \\
\frac{3-v}{1+v} & \text { plane stress }\end{cases}
\end{aligned}
$$

where ( $\mathrm{x}, \mathrm{y})$ is the Cartesian coordinate and the crack with faces exists on the negative $\mathrm{x}$-axis; (r, $\theta$ ) is polar coordinate and $\Theta$ is measured from $\mathrm{x}$-axis in direction of counterclockwise; $\mathrm{k}$ is Kolosov constant; $\mu$ is shear modulus; $\mathrm{E}$ and $\nu$ are Young's modulus and Poisson's ratio, respectively; $u_{0}$ and $v_{0}$ are displacements at the crack tip; $a_{n}$ and $b_{n}$ are coefficients and $\theta_{0}$ is the rigid body rotation with respect to the crack tip. The coefficients of the leading (singular) terms, $a_{1}$ and $b_{1}$, which are relevant to the mode I and mode II stress intensity factors can be expressed as [22]:

$$
\begin{aligned}
& a_{1}=\frac{K_{I}}{\sqrt{2 \pi}} \\
& b_{1}=\frac{K_{I I}}{\sqrt{2 \pi}}
\end{aligned}
$$

where $\mathrm{K}_{\mathrm{I}}$ and $\mathrm{K}_{\mathrm{II}}$ are mode I and mode II stress intensity factors (SIFs) respectively.

Zhao et al. [1] utilized an extrapolation procedure in FE software ANSYS using nodal displacements of a few nodes away from the singularity point at the crack tip. They established a local coordinate where the crack tip lies on origin and the crack faces lie on the negative $\mathrm{x}$-axis. They are selected five nodes; one node at the crack tip and two nodes on each side of the crack face. The stress intensity factor (SIF) at the crack tip has been extrapolated by them as the following [1]:

$$
\begin{aligned}
& u=\frac{K_{1}}{4 G} \sqrt{\frac{r}{2 \pi}}\left[(2 k-1) \cos \frac{\theta}{2}-\cos \frac{3 \theta}{2}\right]-\frac{K_{2}}{4 G} \sqrt{\frac{r}{2 \pi}}\left[(2 k+3) \sin \frac{\theta}{2}+\sin \frac{3 \theta}{2}\right] \\
& v=\frac{K_{1}}{4 G} \sqrt{\frac{r}{2 \pi}}\left[(2 k-1) \sin \frac{\theta}{2}-\sin \frac{3 \theta}{2}\right]-\frac{K_{2}}{4 G} \sqrt{\frac{r}{2 \pi}}\left[(2 k+3) \cos \frac{\theta}{2}+\cos \frac{3 \theta}{2}\right]
\end{aligned}
$$

where: $r$ and $\theta$ are the polar coordinates, $G$ is the shear modulus, $u$ and $v$ are nodal displacement of these nodes, $K_{1}$ and $\mathrm{K}_{2}$ are SIFs for mode I and mode II.

For a cracked body, the equations of corresponding displacement fields near the crack tip, for the plane strain condition, originally introduced by Karihaloo and Xiao [21] and can be expressed as [2]:

$$
\begin{aligned}
u_{x}= & \frac{K_{I}}{4 \mu} \sqrt{\frac{r}{2 \pi}}\left[(5-8 v) \cos \frac{\theta}{2}-\cos \frac{3 \theta}{2}\right]+\frac{K_{I I}}{4 \mu} \sqrt{\frac{r}{2 \pi}}\left[(9-8 v) \sin \frac{\theta}{2}+\sin \frac{3 \theta}{2}\right] \\
& +\left(1-v^{2}\right) \frac{r}{E}\left(T \cos \theta-4 B_{n} \sin \theta\right)+O\left(r^{3 / 2}\right)
\end{aligned}
$$




$$
\begin{aligned}
u_{y}= & \frac{K_{I}}{4 \mu} \sqrt{\frac{r}{2 \pi}}\left[(7-8 v) \sin \frac{\theta}{2}-\sin \frac{3 \theta}{2}\right]-\frac{K_{I I}}{4 \mu} \sqrt{\frac{r}{2 \pi}}\left[(3-8 v) \cos \frac{\theta}{2}+\cos \frac{3 \theta}{2}\right] \\
& -(1+v) \frac{r}{E}\left(v T \sin \theta+4(1-v) B_{n} \cos \theta\right)+O\left(r^{3 / 2}\right)
\end{aligned}
$$

where: $B_{n}$ is the coefficient relevant to Williams' expansion in anti-symmetric mode. $\mu$ is the shear modulus; E is Young's modulus; $\nu$ is Poisson's ratio; $T$ is a constant that acts parallel to the crack surfaces; $u_{x}$ and $u_{y}$ are displacement fields, for the plane strain condition; $(\mathrm{r}, \theta)$ is the polar coordinate and $\mathrm{K}_{\mathrm{I}}$ and $\mathrm{K}_{\mathrm{II}}$ are the mode I and mode II SIF.

The determination of SIF using the crack flank displacements may be obtained as [2]:

$$
\begin{aligned}
& K_{I}=\frac{\mu}{1-v} \sqrt{\frac{\pi}{2 r}}\left[u_{y}(r, \pi)-u_{y}(r,-\pi)\right] \\
& K_{I I}=\frac{\mu}{1-v} \sqrt{\frac{\pi}{2 r}}\left[u_{x}(r, \pi)-u_{x}(r,-\pi)\right]
\end{aligned}
$$

The first order stress field equations for mode I can be expressed as [13]:

$$
\left[\begin{array}{l}
\sigma_{x x} \\
\sigma_{y y} \\
\tau_{x y}
\end{array}\right]=\frac{K_{I}}{\sqrt{2 \pi r}} \cos \frac{\theta}{2}\left[\begin{array}{l}
1-\sin \frac{\theta}{2} \sin \frac{3 \theta}{2} \\
1+\sin \frac{\theta}{2} \sin \frac{3 \theta}{2} \\
\sin \frac{\theta}{2} \cos \frac{3 \theta}{2}
\end{array}\right]
$$

The stress in the z-direction can be written as [13]:

$$
\sigma_{z \chi}= \begin{cases}v\left(\sigma_{x x}+\sigma_{y y}\right)=\frac{2 v K_{I}}{\sqrt{2 \pi r}} \cos \frac{\theta}{2} & \text { (for plane strain) } \\ 0 \quad \text { (for plane stress) } & \end{cases}
$$

For a double edge cracked plate with two symmetric edge cracks having two symmetrical axes, the general stress functions can be written as [23]:

$$
\begin{aligned}
& \varphi(z)=-\frac{2 b}{\pi} \sin ^{-1}\left[\frac{\cos [\pi z /(2 b)]}{\sqrt{1-\sin ^{2}[\pi a /(2 b)]}}\right] E_{0}+i \sqrt{z^{2}-c^{2}} \sum_{k=1}^{m} E_{k} z^{2 k-1}+\sum_{k=1}^{m} F_{k} z^{2 k-1} \\
& \omega(z)=-\frac{2 b}{\pi} \sin ^{-1}\left[\frac{\cos [\pi z /(2 b)]}{\sqrt{1-\sin ^{2}[\pi a /(2 b)]}}\right] E_{0}+i \sqrt{z^{2}-c^{2}} \sum_{k=1}^{m} F_{k} z^{2 k-1}-\sum_{k=1}^{m} F_{k} z^{2 k-1}
\end{aligned}
$$




$$
\begin{aligned}
& \Phi(z)=\cos \left(\frac{\pi z}{2 b}\right) /\left[\cos ^{2}\left(\frac{\pi z}{2 b}\right)-\sin ^{2}\left(\frac{\pi a}{2 b}\right)\right]_{0}^{1 / 2} E_{k=1} \\
& \quad+\frac{i}{\sqrt{z^{2}-c^{2}}} \sum_{k=1}^{m} E_{k}\left[2 k z c^{2 k}(2 k-1) z_{z}^{2 k-2}\right]+\sum_{k}^{m}(2 k-1) F_{k} z^{2 k-2} \\
& K_{I}=\lim _{z \Rightarrow c} 2 \sqrt{2 \pi e^{-i \alpha}(z-c)} \Phi(z) \\
& z=x+i y \\
& i=\sqrt{-1} \\
& c=b-a
\end{aligned}
$$

where: $\Phi(z), \phi(z)$ and $\omega(z)$ are complex stress functions, $\mathrm{c}$ is the half length of the ligament, $2 \mathrm{~b}$ is width of the plate, a is the length of each edge crack, $E_{k}$ and $F_{k}$ are coefficients, $K_{I}$ is the stress intensity factor, $\alpha$ is an angle of inclination of the crack with the $\mathrm{x}$ axis, $\mathrm{k}$ is Kolosov constant.

Empirical formulas for mode I SIF, for a finite cracked plate under tensile stress, $\sigma$, can be written as [24]:

In case of single edge crack

$$
K_{I}=\sigma \sqrt{\pi a}\left[1.122-0.231(a / b)+10.550(a / b)^{2}-21.710(a / b)^{3}+30.382(a / b)^{4}\right]
$$

In case of center crack

$$
K_{I}=\sigma \sqrt{\pi a}\left[\frac{1-0.5(a / b)+0.370(a / b)^{2}-0.044(a / b)^{3}}{\sqrt{1-a / b}}\right]
$$

where: $2 \mathrm{a}$ is the length of crack, $2 \mathrm{~b}$ is the width of plate

In case of double edge crack having two symmetric edge cracks

$$
K_{I}=\sigma \sqrt{\pi a}\left[\frac{1.122-0.561(a / b)-0.015(a / b)^{2}+0.091(a / b)^{3}}{\sqrt{1-a / b}}\right]
$$

where: $a$ is the length of each edge crack, $2 \mathrm{~b}$ is the width of plate

\section{METHODOLOGY}

D plane strain models of single edge cracked plate (SECP), center cracked plate (CCP), and double edge cracked plate (DECP) under tensile stress, are executed in ANSYS, FEA to determine the numerical values of mode I stress intensity factor $\mathrm{K}_{\mathrm{I}}$. The material of the plate is steel with properties Young's modulus of elasticity (E) = 200GPa 
and Poisson's ratio $(v)=0.3$. The geometry and parameters of the plate are length $=$ width $=(2 \mathrm{~b})=0.72 \mathrm{~m}$, the crack length $=(2 \mathrm{a})$, crack length ratio $=(\mathrm{a} / \mathrm{b})$ and uniform tensile stress in the $\mathrm{y}$-direction $=(\sigma)$. In case of double edge cracked plate $(\mathrm{DECP})$, the length of each edge crack $=(a)$, where the length $(2 \mathrm{a})$ is divided into two equal lengths for two cracks at plate edges. In this analysis, the plate is loaded under loads $(\sigma)$ of $50 \mathrm{MPa}, 220 \mathrm{MPa}$ and $350 \mathrm{MPa}$. For every load, the crack length ratio was varied as $0.1,0.25,0.4,0.55$ and 0.7 . Based on symmetry of the plate, half model was considered in case of (SECP) and quarter model was considered in case of (CCP) and (DECP). The plane strain condition is considered and 2D finite element model is established. Eight-node PLANE 183, 2D, structural solid element, was employed in the finite element analysis (FEA) where it is a suitable singular element for accuracy simulation the singularity property at the crack tip [1]. The options for PLANE 183 element assumed in this analysis are quadrilateral of element shape, plane strain of element behavior and pure displacement of element formulation. There are both strain and stress singularities around an elastic crack tip [5]. A much attention for the region around the crack tip must be considered during the meshing in the finite element analysis to produce the singularity in the stresses and strains at the crack tip [25]. In this analysis, the mesh of the region around crack tip was generated using singular elements but irregular elements are used for the generation mesh of the rest region as [15]. Hence, the concentration keypoint at the crack tip has been created. The fracture toughness $\mathrm{K}_{\mathrm{I}}$ was calculated during finite element analysis using the KCALC command as [26]. Geometry, finite element mesh and symmetry boundary conditions for cases (SECP), (CCP), and (DECP), respectively are shown in Figs. 3, 4 and 5 , respectively.

(a)

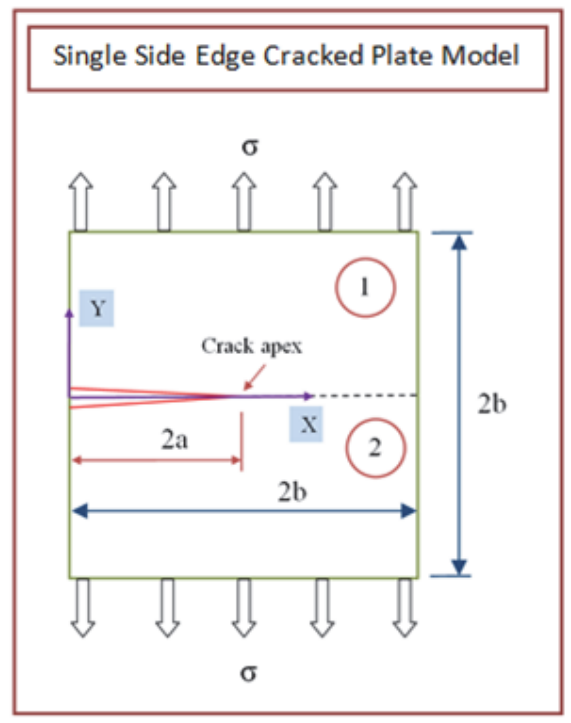

(b)

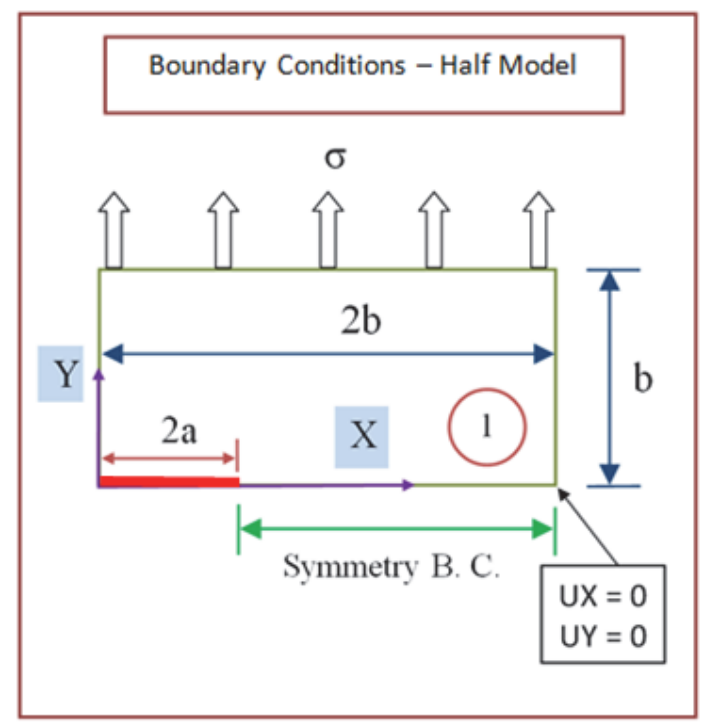

(c)

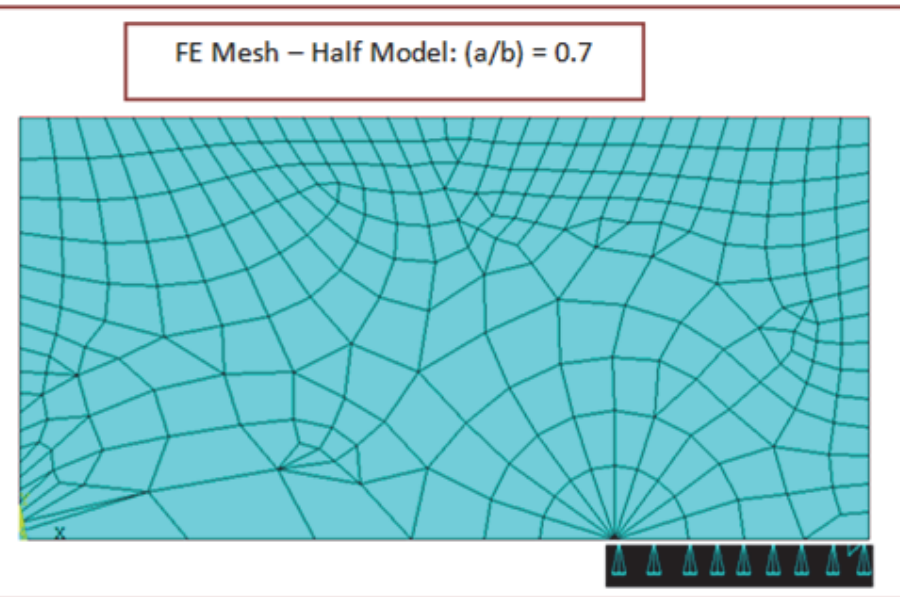

Figure 3: Single edge cracked plate (SECP): (a) full model, (b) symmetry boundary conditions of half model and (c) FE mesh of half model 
The FEA results of Von-Mises stress at crack apex for the cases of (SECP), (CCP) and (DECP), respectively are indicated in Tabs. 1, 2 and 3, respectively. From these Tables it is noticed that the values of Von-Mises stress are the maximum in the case of (SECP) and the minimum in the case of (DECP). The Mode I stress intensity factor $\mathrm{K}_{\mathrm{I}}$ is calculated by using the KCALC command for two cases of (CCP) and (DECP) is depicted in Fig. 6. The FEA Von-Mises stress contour for some cases of (SECP), (CCP) and (DECP) as shown in Fig. 7, indicated that the maximum Von-Mises stress occurs at crack apex.

(a)

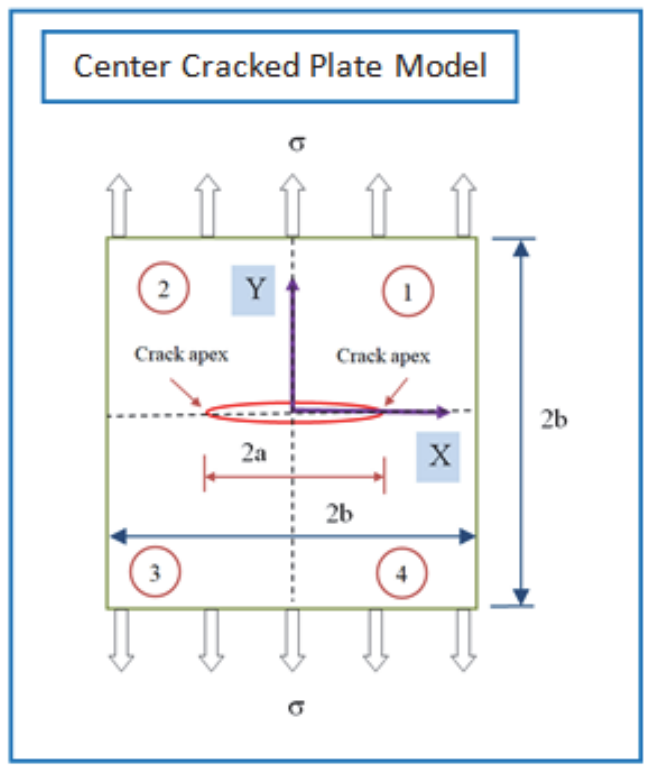

(d)

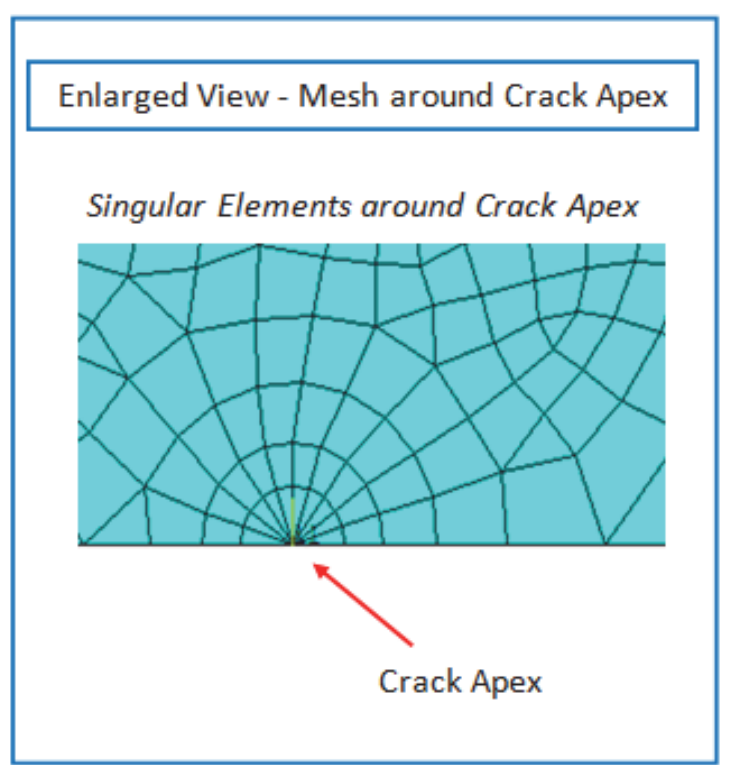

(b)

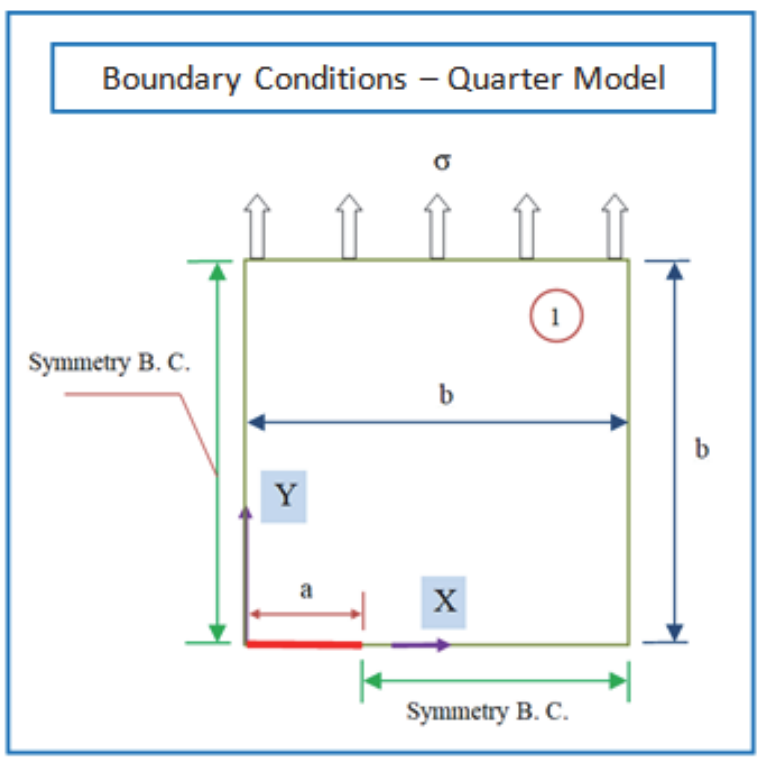

(c)

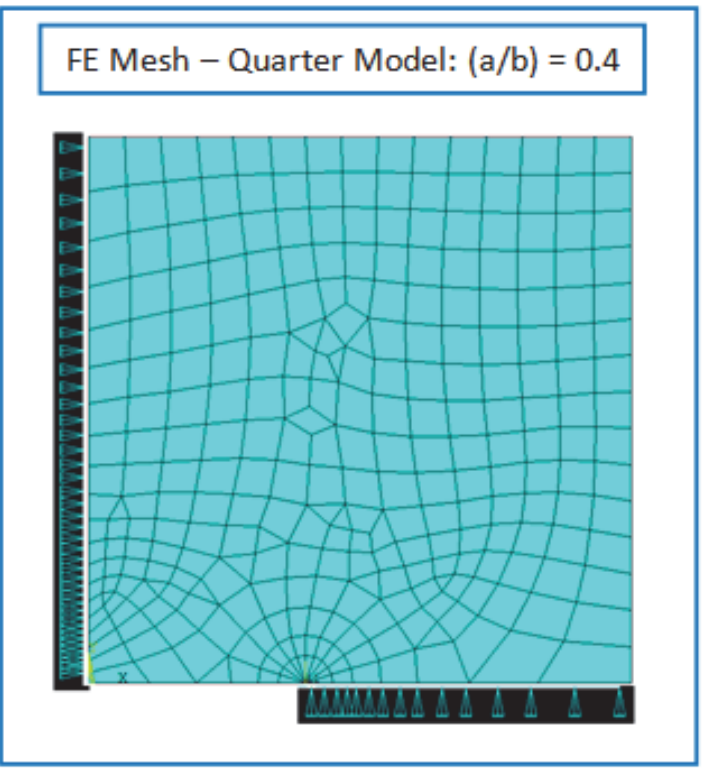

Figure 4: Center cracked plate (CCP): (a) full model, (b) symmetry boundary conditions of quarter model, (c) FE mesh of quarter model, and (d) singular elements around crack apex 
(a)

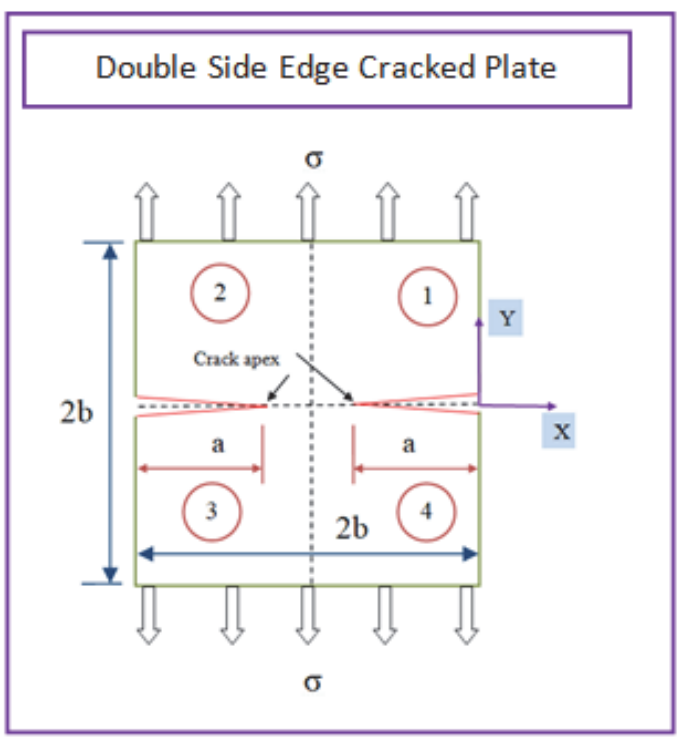

(b)

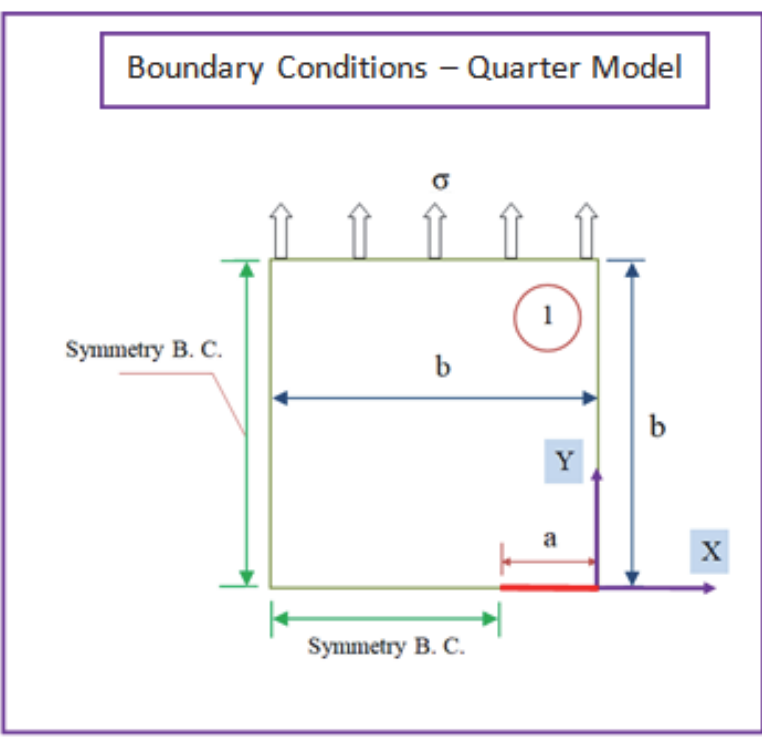

FE Mesh - Quarter Model: $(\mathrm{a} / \mathrm{b})=0.55$

Mesh around Crack Apex

(c)

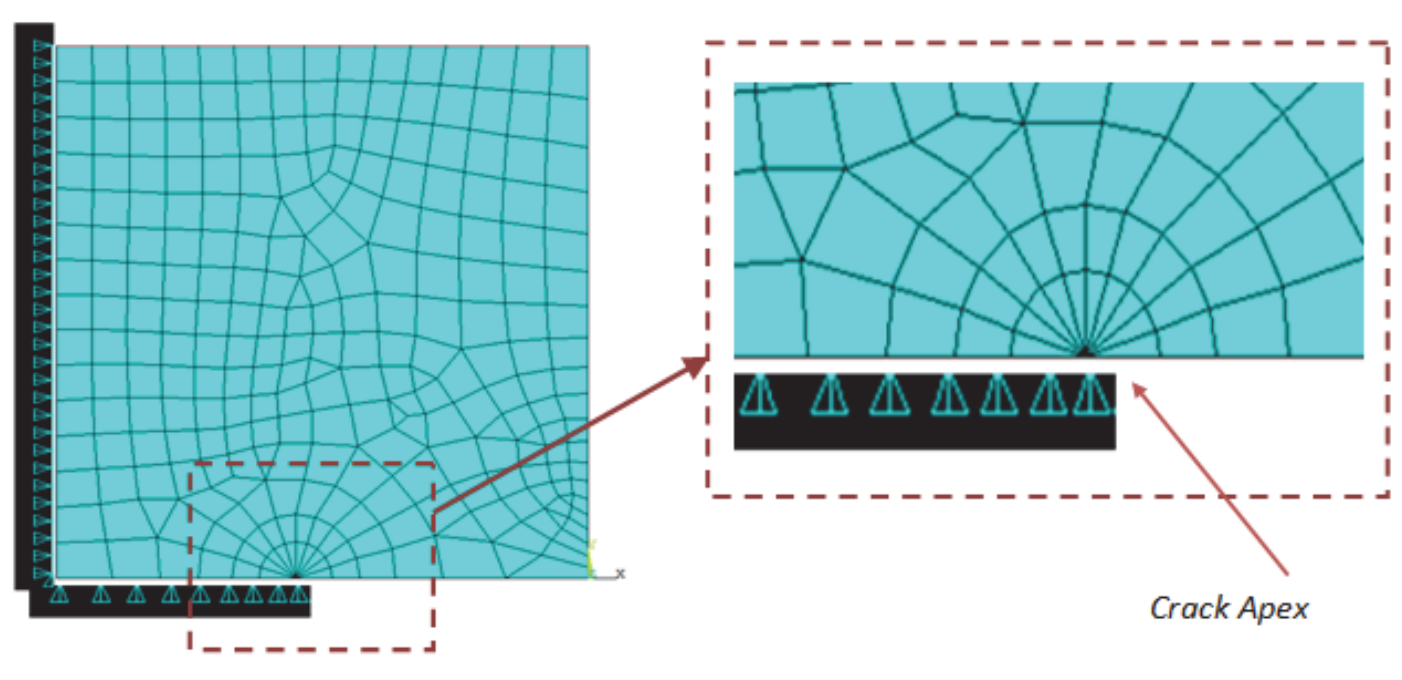

Figure 5: Double edge cracked plate (DECP): (a) full model, (b) symmetry boundary conditions of quarter model, and (c) FE mesh of quarter model

\begin{tabular}{|c|c|c|c|}
\hline Crack length ratio (a/b) & \multicolumn{3}{|c|}{$\begin{array}{l}\text { Single edge cracked plate } \\
\text { Von-Mises stress }(\mathrm{Pa})\end{array}$} \\
\hline 0.1 & $0.144 \times 10^{9}$ & $0.633 \times 10^{9}$ & $0.101 \times 10^{10}$ \\
\hline 0.25 & $0.185 \times 10^{9}$ & $0.813 \times 10^{9}$ & $0.129 \times 10^{10}$ \\
\hline 0.4 & $0.241 \times 10^{9}$ & $0.106 \times 10^{10}$ & $0.169 \times 10^{10}$ \\
\hline 0.55 & $0.341 \times 10^{9}$ & $0.150 \times 10^{10}$ & $0.239 \times 10^{10}$ \\
\hline 0.7 & $0.651 \times 10^{9}$ & $0.286 \times 10^{10}$ & $0.456 \times 10^{10}$ \\
\hline
\end{tabular}

Table 1: FEA Von-Mises stress at crack apex for the case of (SECP). 


\begin{tabular}{|c|c|c|c|}
\hline \multirow[t]{2}{*}{ Crack length ratio $(\mathrm{a} / \mathrm{b})$} & \multicolumn{3}{|c|}{$\begin{array}{l}\text { Center cracked plate } \\
\text { Von-Mises stress }(\mathrm{Pa})\end{array}$} \\
\hline & $\sigma=50(\mathrm{MPa})$ & $\sigma=220(\mathrm{MPa})$ & $\sigma=350(\mathrm{MPa})$ \\
\hline 0.1 & $0.135 \times 10^{9}$ & $0.594 \times 10^{9}$ & $0.945 \times 10^{9}$ \\
\hline 0.25 & $0.145 \times 10^{9}$ & $0.639 \times 10^{9}$ & $0.102 \times 10^{10}$ \\
\hline 0.4 & $0.163 \times 10^{9}$ & $0.716 \times 10^{9}$ & $0.114 \times 10^{10}$ \\
\hline 0.55 & $0.188 \times 10^{9}$ & $0.825 \times 10^{9}$ & $0.131 \times 10^{10}$ \\
\hline 0.7 & $0.226 \times 10^{9}$ & $0.995 \times 10^{9}$ & $0.158 \times 10^{10}$ \\
\hline
\end{tabular}

Table 2: FEA Von-Mises stress at crack apex for the case of (CCP).

\begin{tabular}{|c|c|c|c|}
\hline Crack length ratio (a/b) & \multicolumn{3}{|c|}{$\begin{array}{c}\text { Double edge cracked plate } \\
\text { Von-Mises stress }(\mathrm{Pa})\end{array}$} \\
\hline 0.1 & $0.134 \times 10^{9}$ & $0.59 \times 10^{9}$ & $0.939 \times 10^{9}$ \\
\hline 0.25 & $0.140 \times 10^{9}$ & $0.618 \times 10^{9}$ & $0.983 \times 10^{9}$ \\
\hline 0.4 & $0.147 \times 10^{9}$ & $0.645 \times 10^{9}$ & $0.103 \times 10^{10}$ \\
\hline 0.55 & $0.149 \times 10^{9}$ & $0.657 \times 10^{9}$ & $0.104 \times 10^{10}$ \\
\hline 0.7 & $0.154 \times 10^{9}$ & $0.68 \times 10^{9}$ & $0.108 \times 10^{10}$ \\
\hline
\end{tabular}

Table 3: FEA Von-Mises stress at crack apex for the case of (DECP).

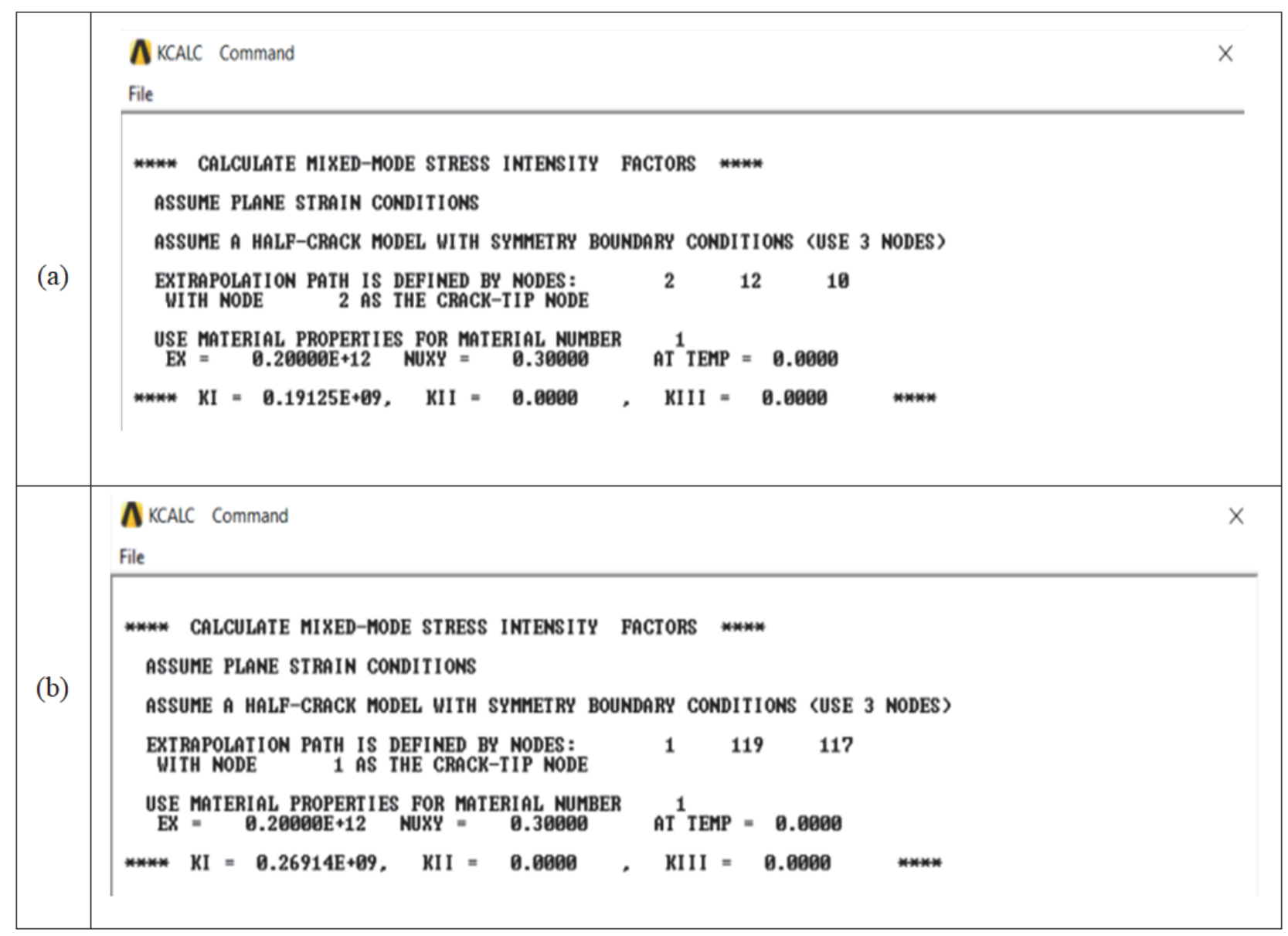

Figure 6: Mode I stress intensity factor $\left(\mathrm{K}_{\mathrm{I}}\right):(\mathrm{a})(\mathrm{CCP}) ;(\mathrm{a} / \mathrm{b})=0.25 ; \sigma=350 \mathrm{MPa},(\mathbf{b})(\mathrm{DECP}) ;(\mathrm{a} / \mathrm{b})=0.7 ; \sigma=220 \mathrm{MPa}$ 


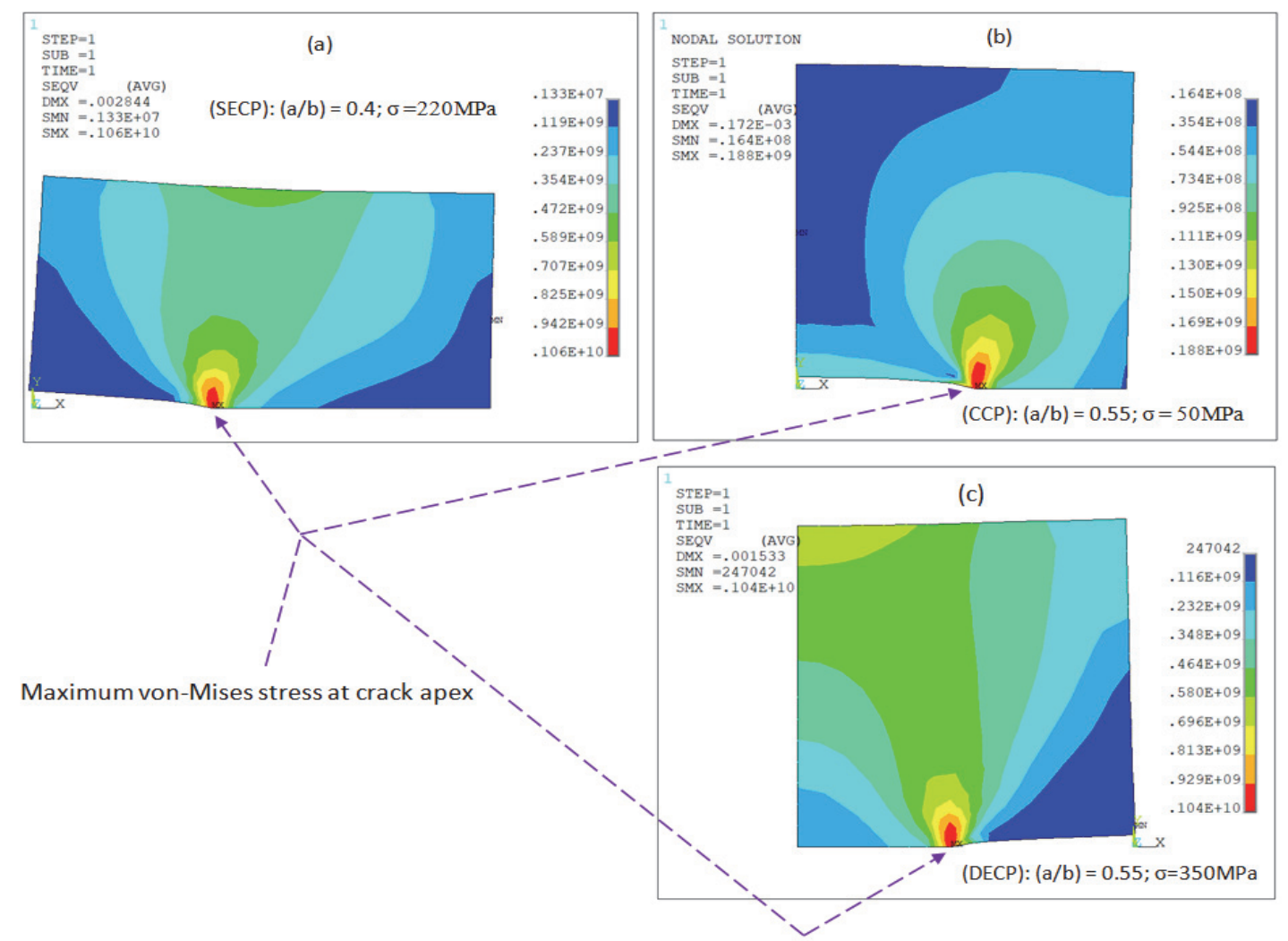

Figure 7: Von-Mises stress contour: (a) $(\mathrm{SECP}) ;(\mathrm{a} / \mathrm{b})=0.4 ; \sigma=220 \mathrm{MPa},(\mathrm{b})(\mathrm{CCP}) ;(\mathrm{a} / \mathrm{b})=0.55 ; \sigma=50 \mathrm{MPa},(\mathbf{c})(\mathrm{DECP}) ;(\mathrm{a} / \mathrm{b})=$ $0.55 ; \sigma=350 \mathrm{MPa}$.

\section{RESULTS AND DISCUSSIONS}

A $\mathrm{s}$ this work focuses on study the influence of crack type, i.e. single edge crack, center crack and double edge crack on crack severity in a finite plate. Hence, this section indicates a comparison of numerical results obtained for (SECP), (CCP) and (DECP) to investigate crack severity. FEA results of fracture toughness (mode I stress intensity factor) for cracked cases of plate with values of tensile stress $50 \mathrm{MPa}, 220 \mathrm{MPa}$ and $350 \mathrm{MPa}$, respectively are shown in Figs. 8, 9 and 10, respectively. These figures revealed the comparison of SIFs obtained from FEA in the following ways:

1. When the tensile stress is kept constant and the crack length is increased, then mode I SIF i.e., fracture toughness at crack apex increases.

2. When the crack length is kept constant and the tensile stress is increased, then the fracture toughness at crack apex increases.

3. When the tensile stress and the crack length are kept constant, the case of single edge cracked plate has the maximum value of fracture toughness at crack apex.

4. When the tensile stress is kept constant and at $(\mathrm{a} / \mathrm{b})=0.55$ and at $(\mathrm{a} / \mathrm{b})=0.7$, the case of double edge cracked plate has the minimum value of fracture toughness at crack apex.

5. When the tensile stress is kept constant, the SIFs for double edge cracked plate are higher with a small difference than those for center cracked plate in case of $(\mathrm{a} / \mathrm{b})=0.1,(\mathrm{a} / \mathrm{b})=0.25$ and $(\mathrm{a} / \mathrm{b})=0.4$.

The results showed little different of SIFs obtained from the double edge and center cracks in case of $(\mathrm{a} / \mathrm{b})=0.1,(\mathrm{a} / \mathrm{b})=$ 0.25 and $(\mathrm{a} / \mathrm{b})=0.4$. Hence, in case of small size cracks the effect of double edge and center cracks on the structural performance of the plate is neearly the same. On the other hand, in case of high size cracks the influence of center cracks on the plate is greater than those of double edge cracks. From the results, a great significant effect is observed in case of single edge cracks on the deterioration of structural performance. 

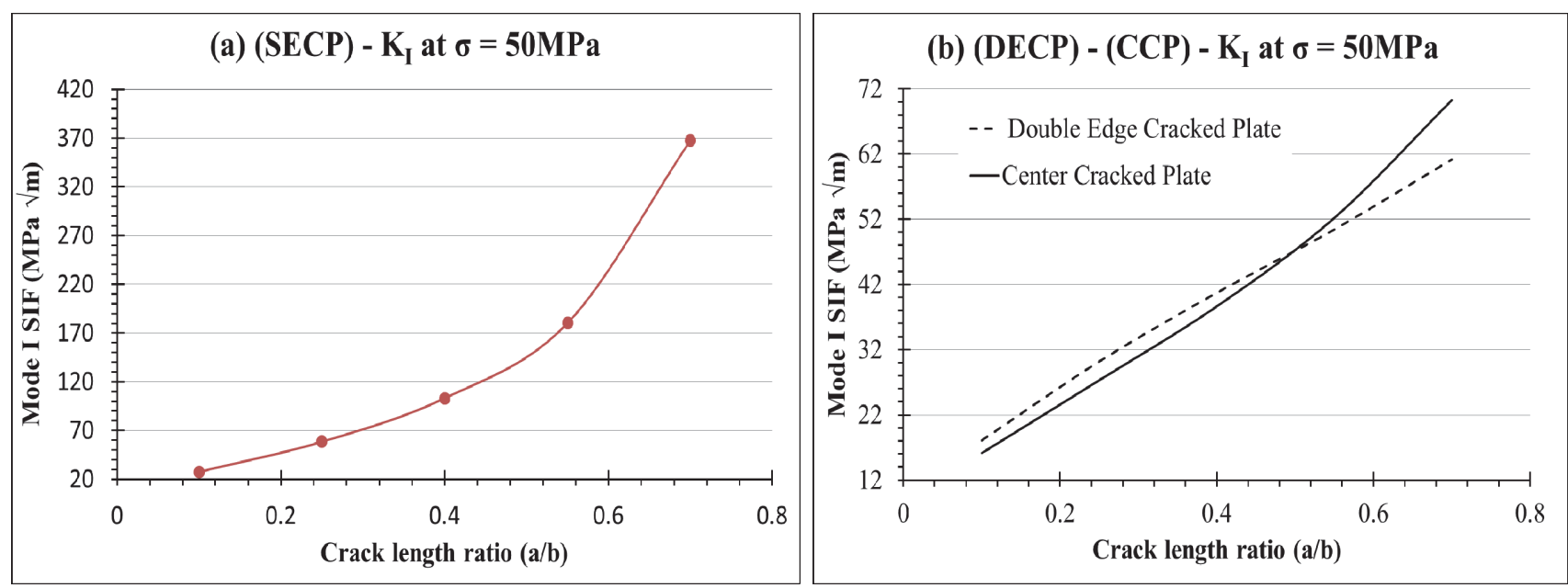

Figure 8: FEA fracture toughness values at $\sigma=50 \mathrm{MPa}$.
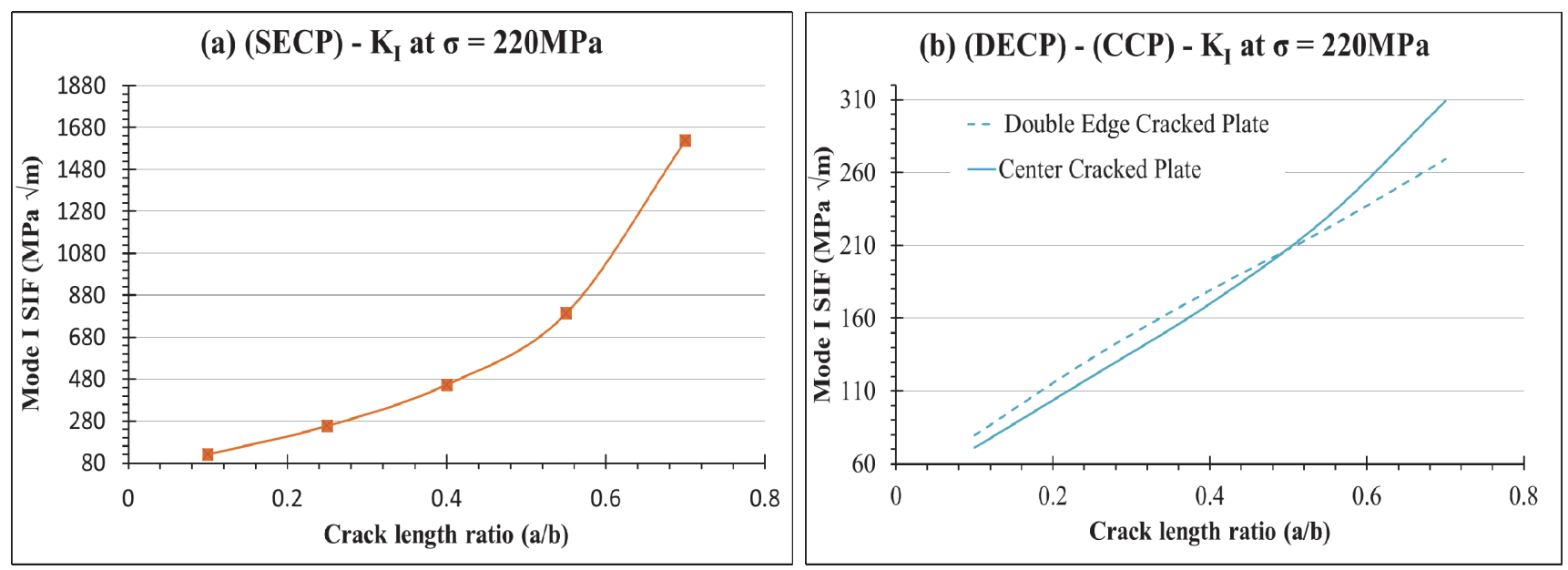

Figure 9: FEA fracture toughness values at $\sigma=220 \mathrm{MPa}$.

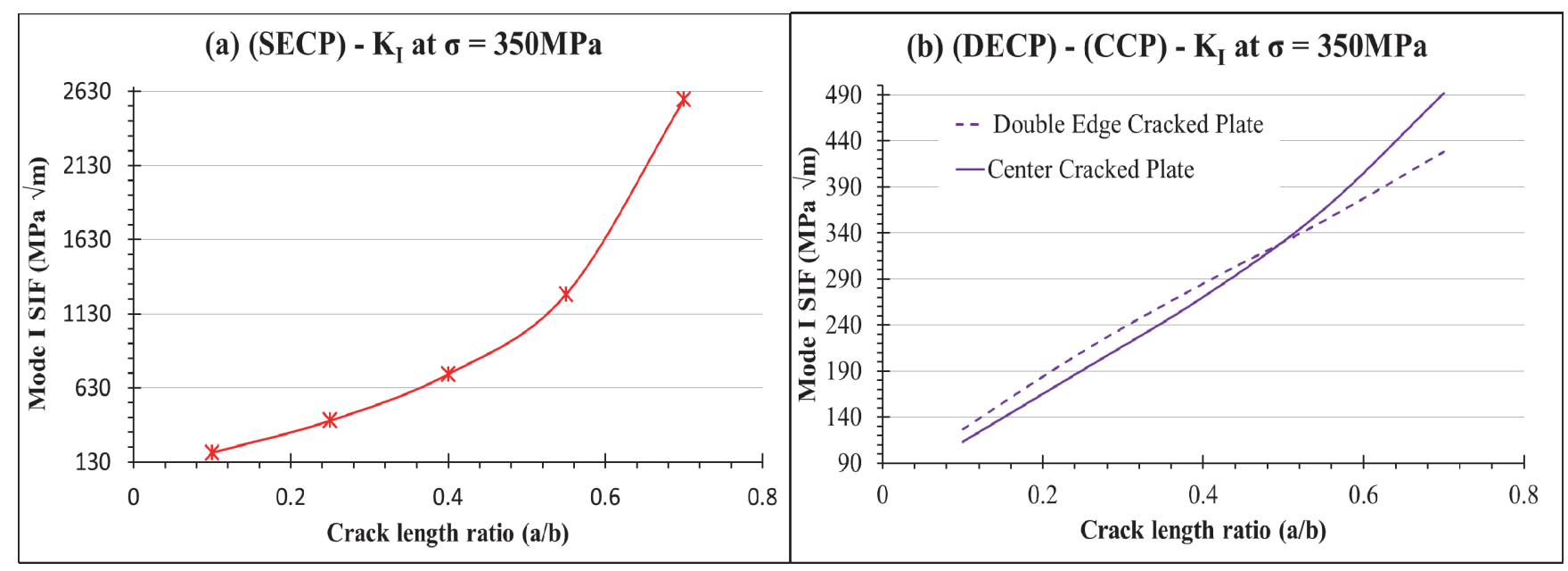

Figure 10: FEA fracture toughness values at $\sigma=350 \mathrm{MPa}$ 


\section{ANALYTICAL SOLUTION FOR SIF CALCULATION}

$\mathrm{T}$ his section validates the numerical results of mode I SIF obtained from finite element analysis (FEA). For this purpose, the values of mode I SIF were approximately calculated for (SECP), (CCP) and (DECP), respectively using Eqn. (22) [24], Eqn. (23) [24] and Eqn. (24) [24], respectively. The comparison between analytical and numerical values of mode I SIF is indicated in Tabs. (4), (5) and (6). It is observed that the results of $\mathrm{K}_{\mathrm{I}}$ obtained from finite element analysis using software ANSYS are with good agreement to those of analytical results and thus verifies the acceptance of the FEA used in the calculation of fracture toughness.

\begin{tabular}{|c|c|c|c|c|c|c|c|c|c|}
\hline \multirow{2}{*}{$\begin{array}{l}\text { Crack } \\
\text { length } \\
\text { ratio } \\
\text { (a/b) }\end{array}$} & \multicolumn{9}{|c|}{$\begin{array}{l}\mathrm{K}_{\mathrm{I}}(\mathrm{Pa} \sqrt{\mathrm{m}}) \text { for single edge cracked plate } \\
\qquad \sigma=220 \mathrm{MPa}\end{array}$} \\
\hline & $\begin{array}{c}\text { Analytical } \\
\text { Eq (22) } \\
{[24]}\end{array}$ & FEA & $\begin{array}{c}\text { Error } \mid \\
(\%)\end{array}$ & $\begin{array}{c}\text { Analytical } \\
\text { Eq (22) } \\
{[24]}\end{array}$ & FEA & $\begin{array}{c}\mid \text { Error } \mid \\
(\%)\end{array}$ & $\begin{array}{c}\text { Analytical } \\
\text { Eq (22) } \\
{[24]}\end{array}$ & FEA & $\begin{array}{c}\text { Error } \mid \\
(\%)\end{array}$ \\
\hline 0.1 & $0.282 \times 10^{8}$ & & 22 & $0.124 \times 10^{9}$ & & 2.2 & $0.197 \times 10^{9}$ & $0.19299 \times 10^{9}$ & 2 \\
\hline & & & & & & & & & 2.3 \\
\hline 0.4 & 0. & $10318 \times 1$ & 3.2 & $0.44 \times 10^{9}$ & $0.45397 x$ & 3. & $0.7 x$ & $0.7222 x$ & 3.2 \\
\hline 0.55 & $7 \times 109$ & & & 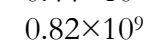 & & & & & 2.9 \\
\hline 0.7 & $0.376 \times 10^{9}$ & $0.36778 \times 10^{9}$ & 2.2 & $0.165 \times 10^{10}$ & $0.16182 \times 10^{10}$ & 1.9 & $0.263 \times 10^{10}$ & $0.25745 \times 10^{10}$ & 2.1 \\
\hline
\end{tabular}

Table 4: Mode I stress intensity factor values obtained analytically and by FEA for the single edge cracked finite plate.

\begin{tabular}{|c|c|c|c|c|c|c|c|c|c|}
\hline \multirow{2}{*}{$\begin{array}{l}\text { Crack } \\
\text { length } \\
\text { ratio } \\
(\mathrm{a} / \mathrm{b})\end{array}$} & \multicolumn{3}{|c|}{$\sigma=50 \mathrm{MPa}$} & \multicolumn{3}{|c|}{$\begin{array}{c}\mathrm{K}_{\mathrm{I}}(\mathrm{Pa} \sqrt{\mathrm{m}}) \text { for center cracked plate } \\
\sigma=220 \mathrm{MPa}\end{array}$} & \multicolumn{3}{|c|}{$\sigma=350 \mathrm{MPa}$} \\
\hline & $\begin{array}{c}\text { Analytical } \\
\text { Eqn. (23) } \\
{[24]}\end{array}$ & FEA & $\begin{array}{c}\mid \text { Error } \mid \\
(\%)\end{array}$ & $\begin{array}{c}\text { Analytical } \\
\text { Eqn. (23) } \\
{[24]}\end{array}$ & FEA & $\begin{array}{c}\mid \text { Error } \mid \\
(\%)\end{array}$ & $\begin{array}{c}\text { Analytical } \\
\text { Eqn. (23) } \\
{[24]}\end{array}$ & FEA & $\begin{array}{c}\mid \text { Error } \mid \\
(\%)\end{array}$ \\
\hline 0.1 & $0.169 \times 10^{8}$ & $0.1615 \times 1 c$ & 4.4 & $0.744 \times 10^{8}$ & $0.711 \times 10^{8}$ & 4.4 & $0.118 \times 10^{9}$ & $0.11304 \times 10^{9}$ & 4.2 \\
\hline & & & & & & 0. & & & \\
\hline 0.4 & $0.372 \times 10^{8}$ & $0.3864 \times 10^{8}$ & 3.9 & $.164 \times 10^{9}$ & $0.170 \times 10^{9}$ & 3.7 & $0.260 \times 10^{9}$ & $0.27048 \times 10^{9}$ & 4.03 \\
\hline 0.55 & $0.488 \times 10^{8}$ & $0.522 \times 10^{8}$ & 6.97 & $0.215 \times 10^{9}$ & $0.22967 \times 10^{9}$ & 6.8 & $0.341 \times 10^{9}$ & $0.36539 \times 10^{9}$ & 7.2 \\
\hline 0.7 & $0.663 \times 10^{8}$ & $0.70257 \times 10^{8}$ & 5.97 & $0.292 \times 10^{9}$ & $0.30913 \times 10^{9}$ & 5.87 & $0.464 \times 10^{9}$ & $0.4918 \times 10^{9}$ & 6 \\
\hline
\end{tabular}

Table 5: Mode I stress intensity factor values obtained analytically and by FEA for the center cracked finite plate.

\begin{tabular}{|c|c|c|c|c|c|c|c|c|c|}
\hline \multirow{2}{*}{$\begin{array}{l}\text { Crack } \\
\text { length } \\
\text { ratio } \\
(\mathrm{a} / \mathrm{b})\end{array}$} & \multicolumn{9}{|c|}{$\begin{array}{c}\mathrm{K}_{\mathrm{I}}(\mathrm{Pa} \sqrt{\mathrm{m}}) \text { for double edge cracked plate } \\
\qquad \sigma=220 \mathrm{MPa}\end{array}$} \\
\hline & $\begin{array}{c}\text { Analytical } \\
\text { Eqn. (24) } \\
{[24]}\end{array}$ & FEA & $\begin{array}{c}\mid \text { Error } \mid \\
(\%)\end{array}$ & $\begin{array}{c}\text { Analytical } \\
\text { Eqn. (24) } \\
\text { [24] }\end{array}$ & FEA & $\begin{array}{c}\mid \text { Error } \mid \\
(\%)\end{array}$ & $\begin{array}{c}\text { Analytical } \\
\text { Eqn. (24) } \\
{[24]}\end{array}$ & FEA & $\begin{array}{c}\mid \text { Error } \mid \\
(\%)\end{array}$ \\
\hline 0.1 & $0.189 \times 10^{8}$ & $0.18091 \times 10^{8}$ & 4.3 & $0.831 \times 10^{8}$ & $0.796 \times 10^{8}$ & 4.2 & $0.132 \times 10^{9}$ & $0.12664 \times 10^{9}$ & 4.1 \\
\hline 0.25 & & & 0.1 & & & 0.1 & & & \\
\hline 0.4 & & & 4.1 & & & 4.2 & & & 4.04 \\
\hline 0.55 & $0.484 \times 10^{8}$ & $0.50434 \times 10^{8}$ & 4.2 & $0.213 \times 10^{9}$ & $0.22191 \times 10^{9}$ & 4.2 & $0.339 \times 10^{9}$ & $0.35304 \times 10^{9}$ & 4.1 \\
\hline 0.7 & $0.612 \times 10^{8}$ & $0.61169 \times 10^{8}$ & 0.05 & $0.269 \times 10^{9}$ & $0.26914 \times 10^{9}$ & 0.05 & $0.428 \times 10^{9}$ & $0.42818 \times 10^{9}$ & 0.04 \\
\hline
\end{tabular}

Table 6: Mode I stress intensity factor values obtained analytically and by FEA for the double edge cracked finite plate.

\section{CONCLUSION}

$\mathrm{F}$ EA were performed for cases of cracked finite plate with three types of crack, single edge crack, center crack and double edge crack under tensile stress with different values, then the numerical values of Von-Mises stress and mode I SIF are obtained. From the comparison of the FEA results for the three types of crack, it is observed that the FEA values of Von-Mises stress and mode I SIF at crack tip are the maximum in case of single edge cracked plate. FEA values of Von-Mises stress at crack tip are moderate in case of center cracked plate and the minimum in case of 
double edge cracked plate. As the severity of crack is proportional to values of fracture toughness and Von-Mises stress at crack apex, hence from the previous observations of the results, it can be considered that severity of single edge crack type is the maximum. On the other hand, the crack severity in case of center crack is moderate and in case of double edge crack is the minimum. The crack geometry which is asymmetry in case of (SECP) and symmetric in the two cases (CCP) and (DECP) was vital to interpret the variation in the obtained results for SIF. AS a result, when plate having a single edge crack, there would be high significant effect on SIF and this effect would be less in the two cases with double edge crack and center crack. The accuracy of numerical models is validated by comparing values of mode I SIF obtained by analytical and FEA, where the comparison exhibited a good convergence.

\section{REFERENCES}

[1] Zhao, F., AiQun, L., HaiYing, B., Hao, W. (2018). Calculation of stress intensity factor in two-dimensional cracks by strain energy density factor procedure. Sci. China Technol. Sci. 61(4), pp. 542-550, DOI: $10.1007 / \mathrm{s} 11431-017-9186-9$.

[2] Chen, C.-H., Wang, C.-L. (2008). Stress intensity factors and T-stresses for offset double edge-cracked plates under mixed-mode loadings. Int. J. Fract. 152, pp. 149-162, DOI: 10.1007/s10704-008-9276-5.

[3] Yamamoto, Y., Tokuda, N. (1973). Determination of stress intensity factors in cracked plates by the finite element method. Int. J. Numer. Methods Eng. 6, pp. 427-439.

[4] Zhong-liang, R., Hong-bo, Z., Shun-de, Y. (2013). Evaluation of mixed-mode stress intensity factors by extended finite element method. J. Cent. South Univ. 20, pp. 1420-1425, DOI: 10.1007/s11771-013-1630-8.

[5] Mukhopadhyay, N.K., Maiti, S.K., Kakodkar, A. (2000). A review of SIF evaluation and modelling of singularities in BEM. Comput. Mech. 25, pp. 358-375, DOI: 10.1007/s004660050483.

[6] Byskov, E. (1970). The Calculation of stress intensity factors using the finite element method with cracked elements. Int. J. Fract. Mech. 6(2), pp. 159-167, DOI: 10.1007/BF00189823.

[7] Mohammed, B., Boualem, S., Mokadem, S., Bouchra, Z., Khacem, K. (2019). Modeling of a cracked and repaired Al 2024T3 aircraft plate: effect of the composite patch shape on the repair performance. Frattura ed Integrità Strutturale, 50, pp. 68-85, DOI: 10.3221/IGF-ESIS.50.08.

[8] Bhagat, R.K., Singh, V.K. (2013). Effect of specimen geometry on stress intensity factors of inclined crack by finite element method. J. Fail. Anal. Prev. 13(4), pp. 463-469. DOI: 10.1007/s11668-013-9697-y.

[9] Lou, B., Barltrop, N. (2020). Universal hybrid method and approximate closed-form solution for V-notched and Vnotch-cracked plate under tensile and in-plane bending. Theor. Appl. Fract. Mech. 108, 102579, DOI: $10.1016 /$ j.tafmec.2020.102579.

[10] Ismail, A.E., Awang, M.K., Tobi, A.M., Ahmad, M.H. (2017). Mode I stress intensity factors of slanted cracks. ARPN J. Eng. Appl. Sci. 12(10), pp. 3189-3194.

[11] Souiyah, M., Alshoaibi, A., Muchtar, A., Ariffin, AK. (2008). Finite element model for linear-elastic mixed mode loading using adaptive mesh strategy. J. Zhejiang Univ. Sci. A 9(1), pp. 32-37, DOI: 10.1631/jzus.A072176.

[12] El Fakkoussi, S., Moustabchir, H., Elkhalfi, A., Pruncu, C.I. (2019). Computation of the stress intensity factor KI for external longitudinal semi-elliptic cracks in the pipelines by FEM and XFEM methods. Int. J. Interact. Des. Manuf. (IJIDeM) 13, pp. 545-555, DOI: 10.1007/s12008-018-0517-1.

[13] Perez, N. (2004). Fracture Mechanics, Boston, Kluwer Academic Publishers.

[14] Arunkumar, S., Nithin, V.K. (2020). Estimation of Stress Intensity Factor of Multiple Inclined Centre Cracks under Biaxial Loading. J. Fail. Anal. Prev. 20(6), pp. 2040-2058, DOI: 10.1007/s11668-020-01019-0.

[15] Azlan, M.A., Ismail, A.E. (2015). Effect of Mechanical Mismatch on the Stress Intensity Factors of Inclined Cracks under Mode I Tension Loading. Appl. Mech. Mater. 773-774, pp. 129-133, DOI: 10.4028/www.scientific.net/AMM.773-774.129.

[16] Zhu, N., Oterkus, E. (2020). Calculation of stress intensity factor using displacement extrapolation method in peridynamic framework. J. Mech. 36(2), pp. 235-243, DOI : 10.1017/jmech.2019.62.

[17] Mohsin, N.R. (2015). Static and dynamic analysis of center cracked finite plate subjected to uniform tensile stress using finite element method. Int. J. Mech. Eng. Technol. 6(1), pp. 56-70.

[18] Soliman, E.S.M.M. (2019). Investigation of Crack Effects on Isotropic Cantilever Beam. J. Fail. Anal. Prev. 19(6), pp. 1866-1884, DOI: $10.1007 / \mathrm{s} 11668-019-00796-7$.

[19] Williams, M.L. (1957). On the stress distribution at the base of a stationary crack. J. Appl. Mech. 24(1), pp. 109-114, DOI: $10.1115 / 1.4011454$. 
[20] Owen, D.R.J., Fawkes, A.J. (1983). Engineering Fracture Mechanics: Numerical Methods and Applications, Swansea, U.K., Pineridge Press Ltd.

[21] Karihaloo, B.L., Xiao, Q.Z. (2001). Accurate determination of the coefficients of elastic crack tip asymptotic field by a hybrid crack element with p-adaptivity. Eng. Fract. Mech. 68(15), pp. 1609-1630, DOI: 10.1016/S0013-7944(01)00063-7.

[22] Xiao, Q.Z., Karihaloo, B.L., Liu, X.Y. (2004). Direct determination of SIF and higher order terms of mixed mode cracks by a hybrid crack element. Int. J. Fract. 125, pp. 207-225, DOI: 10.1023/B:FRAC.0000022229.54422.13.

[23] Cheung, Y.K., WOO, C.W., Wang, Y.H. (1988). The stress intensity factor for a double edge cracked plate by boundary collocation method. Int. J. Fract. 37, pp. 217-231, DOI: $10.1007 /$ BF00045864.

[24] Tada, H., Paris, P.C., Irwin, G.R. (2000). The Stress Analysis of Cracks Handbook, third ed., ASME Press.

[25] Soliman, E.S.M.M. (2020). Investigation of Modal and Damage Parameters of Isotropic Cantilever Beam under Double-Sided Crack. J. Fail. Anal. Prev. 20(1), pp. 120-136, DOI: 10.1007/s11668-020-00806-z.

[26] Begum, Y., Bharath, K.N., Doddamani, S., Rajesh, A.M., Kaleemulla, K.M. (2020). Optimization of Process Parameters of Fracture Toughness Using Simulation Technique Considering Aluminum-Graphite Composites. Trans. Indian Inst. Met. 73(12), pp. 3095-3103, DOI: 10.1007/s12666-020-02113-5. 